\title{
PSYCHIATRIC DISORDERS AND DRIVER SAFETY: A SYSTEMATIC REVIEW
}

\author{
Jessica Williams, Stephen Tregear, \& Arit Amana \\ MANILA Consulting Group, Inc. \\ McLean, Virginia, USA \\ Email: jwilliams@manilaconsulting.net
}

\begin{abstract}
Summary: Driving is a complicated psychomotor performance that depends on the driver's ability to maintain effective and reliable control of his or her vehicle; respond to the road, traffic, and other external clues; and follow the "rules of the road". Psychiatric disorders may interfere with any of the aforementioned driving skills to a significant degree, resulting in impaired driving ability. A systematic review and meta-analysis was conducted to examine the relationship between psychiatric disorders and driver safety. The relationship between driver safety and four subgroups of psychiatric disorders was examined, as well as the relationship between crash risk and personality disorder traits. Our results indicate that, while the possibility of an increased crash risk among drivers with psychiatric disorders cannot be ruled out, the evidence concerning crash risk for drivers with psychiatric disorders is inconclusive. Current evidence concerning crash risk among drivers with psychotic, mood, anxiety or personality disorders is inconclusive, although some evidence suggests that individuals with mood disorders are at increased risk for crash. The evidence also suggests an association between certain traits of patients with personality disorders (including aggression, hostility, impulsivity, disregard for law, and various psychological symptoms) and increased crash risk. These results underscore the necessity of more research in the area of psychiatric disorders and driver safety.
\end{abstract}

\section{INTRODUCTION}

Driving is a complicated psychomotor performance that depends on fine coordination between the sensory and motor systems. Many health conditions exist which have the potential to impair perception, cognition (including alertness, attitude to risk, and recall) and/or motor function and, as a result, can make driving less safe. Psychiatric disorders may interfere with an individual's driving skills to a significant degree, resulting in impaired driving ability. Insight is critical for drivers to drive within their limitations and to know how and when these limitations change. Poor insight in patients with psychiatric illness may be evidenced by noncompliance with treatment, trivializing their role in a crash, or repeated involuntary admissions to hospital (often as a result of discontinuing prescribed medication). In individuals with personality disorders, some personality traits which are part of the disorder may be related to behavior which may be associated with an increased risk of motor vehicle crash. The purpose of this study was to summarize the available data pertaining to the relationship between psychiatric disorders and driver safety. We also examined the relationship between driver safety and four subgroups of Psychiatric Disorders: Psychotic Disorders, Mood Disorders, Anxiety Disorders, \& Personality Disorders. Lastly, we examined the association of personality disorder traits and driver safety. 


\section{METHODS}

To meet the aims of this study, a systematic review of the literature was conducted. We synthesized available data from published studies that examined the risk of motor vehicle crash among drivers with a psychiatric disorder. A total of seven electronic databases (MEDLINE, PubMed (preMEDLINE), EMBASE, PsycINFO, CINAHL, TRIS, and the Cochrane Library) were searched through January 28, 2008. In addition, we examined the reference lists of all obtained articles with the aim of identifying relevant articles not identified by our electronic searches. Hand searches of the gray literature were also performed. Admission of an article into an evidence base was determined by the following formal, a priori retrieval and inclusion criteria: 1) English language publications, 2) full-length articles, 3) enrolled $\geq 10$ subjects, 4) subjects must be $\geq 18$ years, 5) attempted to directly determine the risk for a motor vehicle crash (risk for a fatal or nonfatal crash) associated with psychiatric disorder (specifically, psychotic disorder, mood disorder, anxiety disorder, or personality disorder), and crash risk among individuals with personality disorder compared to individuals with no such disorder. Studies must have used a direct measure of crash (not indirect measures, such as driving simulator data). When possible, random-effects meta-analyses were used to pool data from studies.

\section{RESULTS}

\section{Psychiatric Disorders and Crash Risk}

Eight articles met the inclusion criteria for the relationship between psychiatric disorders and crash risk (Armstong \& Whitlock, 1980; Buttiglieri \& Guenette, 1967; Crancer \& Quiring, 1969; Edlund et al., 1989; Foley et al., 1995; Wear, 1985; Waller, 1965; Koepsell et al., 1994). The crash rate ratios for these studies are presented in Table 1. Six studies reported more crashes among drivers with psychiatric disorders compared to other drivers (Edlund et al., 1989; Foley et al., 1995; Crancer and Quiring, 1969; Koepsell et al., 1994; Armstrong and Whitlock, 1980; Waller, 1965); although only two of these studies showed a statistically significant difference between groups (Wear, 1985; Waller, 1965). Two studies reported fewer crashes among drivers with psychiatric disorders (Buttiglieri \& Guenette, 1967; Wear, 1985), but only the Wear study showed a statistically significant difference.

Table 1. Crash Rate Ratio for Drivers with History of a Psychiatric Disorder

\begin{tabular}{|c|c|c|c|c|c|}
\hline Reference & Year & $\begin{array}{c}\text { Psychiatric disorder } \\
\text { studied }\end{array}$ & $\begin{array}{l}\text { Rate Ratio } \\
(95 \% \mathrm{CI})^{*}\end{array}$ & $P=$ & $\begin{array}{c}\text { Evidence of } \\
\text { increased } \\
\text { Crash Risk }\end{array}$ \\
\hline Armstrong and Whitlock & 1980 & (not specific disorder) & $1.345(0.541-3.346)$ & 0.638 & No \\
\hline Buttiglieri and Guenette & 1967 & (not specific disorder) & $0.872(0.576-1.320)$ & 0.517 & No \\
\hline Crancer and Quiring & 1969 & (not specific disorder) & $1.466(0.925-2.323)$ & 0.103 & No \\
\hline Edlund et al. & 1989 & Schizophrenic Disorder & $1.111(0.431-2.867)$ & 0.828 & No \\
\hline Foley et al. & 1995 & Mood Disorder & $1.520(0.797-2.899)$ & 0.204 & No \\
\hline Wear & 1985 & (not specific disorder) & $0.555(0.315-0.977)$ & 0.041 & No \\
\hline Waller & 1965 & (not specific disorder) & $2.063(1.395-3.052)$ & 0.000 & Yes \\
\hline Koepsell et al. & 1994 & Mood Disorder & Odds Ratio: $1.7(0.9-3.1)$ & NR & No \\
\hline
\end{tabular}

*Calculated by ECRI Institute; NR = Not Reported 
The findings from seven studies could be combined in a quantitative analysis (Figure 1). A formal assessment of these data for quantitative consistency found that the findings of the seven cohort studies were not consistent $\left(\mathrm{I}^{2}=66.7 \%\right)$, which precluded obtaining a single estimate of effect (generally, an $\mathrm{I}^{2}$ value of $\leq 50 \%$ indicates greater homogeneity among studies). However, we combined the crash risk ratio data in a random-effects meta-analysis to determine whether an elevated crash risk was associated with psychiatric disorders. Pooling of the data from these studies found no statistically significant difference in crash risk between drivers with psychiatric disorders and drives without psychiatric disorders (CI: 0.827, 1.730). However, the possibility of an increased crash risk for some drivers with psychiatric disorders could not be ruled out. It is important to note that patient populations in these studies were unlikely to have included individuals with severe symptoms who would be more likely to have impaired driving ability.

\begin{tabular}{|c|c|c|c|c|c|c|c|c|}
\hline \multirow[t]{2}{*}{ Study name } & \multicolumn{5}{|c|}{ Statistics for each study } & \multicolumn{3}{|c|}{ Rate ratio and $95 \% \mathrm{Cl}$} \\
\hline & $\begin{array}{l}\text { Rate } \\
\text { ratio }\end{array}$ & $\begin{array}{l}\text { Lower } \\
\text { limit }\end{array}$ & $\begin{array}{c}\text { Upper } \\
\text { limit }\end{array}$ & Z-Value & p-Value & & & \\
\hline Waller & 2.063 & 1.395 & 3.052 & 3.626 & 0.000 & & & \\
\hline Buttiglieri & 0.872 & 0.576 & 1.320 & -0.649 & 0.517 & & & \\
\hline Crancer & 1.466 & 0.925 & 2.323 & 1.630 & 0.103 & & & \\
\hline Armstrong & 1.345 & 0.541 & 3.346 & 0.638 & 0.523 & & & \\
\hline Wear & 0.555 & 0.315 & 0.977 & -2.042 & 0.041 & & & \\
\hline Edlund & 1.111 & 0.431 & 2.867 & 0.218 & 0.828 & & & \\
\hline Foley & 1.520 & 0.797 & 2.899 & 1.271 & 0.204 & & & \\
\hline Summary & NC & 0.827 & 1.730 & 0.950 & 0.342 & & & $\mid$ \\
\hline & & & & & & 0.01 & 0.1 & 100 \\
\hline
\end{tabular}

$* \mathrm{NC}=$ not calculated

Figure 1. Crash Risk for Individuals with a Psychiatric Disorder

Psychotic disorders and crash risk. Four studies specifically addressed the effect of psychotic disorders on crash risk (Armstrong \& Whitlock, 1980; Crancer \& Quiring, 1969; Edlund et al., 1989; Wear, 1985). One study reported fewer crashes among patients with a psychotic disorder compared to control drivers (Wear, 1985), while three included studies reported more crashes among drivers with a psychotic disorder (Crancer \& Quiring, 1969; Armstrong \& Whitlock, 1980; Edlund et al., 1989), although the latter three studies did not show a statistically significant between-group difference in crash risk. Homogeneity testing found the findings of the four studies to be consistent $\left(\mathrm{I}^{2}=45.1 \%\right)$. Random-effects meta-analysis found that the $95 \% \mathrm{CI}$ for the crash rate risk associated with psychotic disorders overlaps with 1, and the between-group difference in crash rate was not statistically significant. Currently available evidence does not suggest an increased crash risk for individuals with psychotic disorders compared to individuals without these disorders, but an increased crash risk cannot be ruled out.

Mood disorders and crash risk. Three studies specifically addressed the effect of mood disorders on crash risk (Armstrong \& Whitlock, 1980; Foley et al., 1995; Koepsell et al., 1994). All three studies reported a higher crash rate among drivers with a mood disorder (specifically depression) compared to control drivers, although the difference did not reach statistical significance in any of these studies. The small number of studies did not allow for meta-analysis. Although evidence 
suggests the possibility that individuals with mood disorders are at an increased risk for a motor vehicle crash compared with drivers who do not have mood disorders, more evidence is needed to reach a firm conclusion.

Anxiety disorders and crash risk. One study was identified examining the relationship between anxiety disorders and crash risk (Crancer \& Quiring, 1969). This study found a slightly higher crash rate for psychoneurotic disorders, compared to a reference population; however, this difference was not statistically significant. One other study (Armstrong \& Whitlock, 1980) reported the number of crashes for drivers with neuroses - a category that could include anxiety disorders. However, the authors did not define what types of patients were included in this category; hence the corresponding data was not evaluated. A paucity of evidence prevents us from being able to draw an evidence-based conclusion about the effects of anxiety disorders on the risk of motor vehicle crash.

Personality disorders and crash risk. Three studies specifically addressed the effect of personality disorders on crash risk (Armstrong \& Whitlock, 1980; Crancer \& Quiring, 1965; Wear, 1985). Two studies reported more crashes among drivers with a personality disorder compared to control drivers (Crancer \& Quiring, 1965; Armstrong and Whitlock, 1980), while the remaining study (Wear, 1985) reported fewer crashes among drivers with a personality disorder. However, no studies found a statistically significant between-group difference in crash rates. Homogeneity testing found that the results of the three studies were inconsistent $\left(\mathrm{I}^{2}=\right.$ $57.8 \%$ ). Random-effects meta-analysis found that the $95 \% \mathrm{CI}$ of the crash RR associated with personality disorders is $0.532-2.446$; this difference was not statistically significant $(\mathrm{p}=0.182)$. Due to inconsistencies in the available evidence, we are precluded from drawing an evidencebased conclusion pertaining to the strength of the relationship between personality disorders and crash risk at this time.

\section{Personality Disorder Traits and Crash Risk}

Twenty-one articles were found to meet the inclusion criteria for the relationship between personality disorder traits and crash risk (Alparslan et al., 1999; Bell et al, 2000; Blows et al. 2005; Deery \& Fildes, 1999; Fong et al., 2001; Gulliver \& Begg, 2007; Karlsson et al., 2003; Kontogiannis, 2006; Lajunen et al., 2001; Malta et al., 2005; Mayer \& Treat, 1977; Nabi et al., 2005; Nabi et al., 2007; Parker et al., 1995; Rajalin, 1994; Schwebel et al., 2006; Sullman et al., 2002; Sumer, 2003; Turner \& McClure, 2004; Verschuur \& Hurts, 2008; Wells-Parker et al., 2002). Overall, the included studies suggest that traits such as aggression, hostility, impulsivity, disregard for laws (i.e., attitude toward traffic law violations), and various psychological symptoms are associated with an increase in crash risk. The same can be said of behaviors such as risky driving and violation of traffic laws. In turn, behaviors such as risky driving are associated with aggression, impulsivity, and psychological symptoms such as anxiety, depression, and psychosis. Violation of traffic laws is associated with risky driving and aggression. Table 2 provides a summary of the association between factors and outcomes. 
Table 2. Associations between Personality Disorder Traits and Driver Safety

\begin{tabular}{l} 
Aggression \\
\cline { 3 - 5 }
\end{tabular}

\section{DISCUSSION}

The evidence concerning crash risk for drivers with psychiatric disorders is inconclusive. The pooling of data from seven studies found no statistically significant difference in crash risk between drivers with psychiatric disorders and drivers without psychiatric disorders. However, the possibility of an increased crash risk for some drivers with psychiatric disorders could not be ruled out. Evidence also does not suggest an increased crash risk for individuals with psychotic, anxiety or personality disorders, when compared to individuals without these disorders, but an increased crash risk cannot be ruled out. Although evidence suggests the possibility that individuals with mood disorders are at an increased risk for a motor vehicle crash when compared with drivers who do not have mood disorders, more evidence is needed to reach a firm conclusion. Finally, the evidence suggests an association between certain traits of individuals with personality disorders (including aggression, hostility, impulsivity, disregard for law, and various psychological symptoms) and increased crash risk. These findings have important implications for regulatory agencies with responsibility for road safety; particularly agencies that regulate safety sensitive industries.

\section{ACKNOWLEDGEMENTS}

This research was performed under United States Department of Transportation contract number GS-10F-0177N/DTMC75-06-F-00039. The opinions of the authors expressed herein do not necessarily state or reflect those of the United States Government.

\section{REFERENCES}

Alparslan, B., Dereboy, C., Oner Savk, S., Kaynak, H., Dereboy, I.F., Cullu, E., Ozkan, I., \& Ayaz, S. (1999). The relationship of traffic accidents with personality traits. Journal of Traffic Medicine, 27(1-2), 25-30.

Armstrong, J. L., \& Whitlock, F. A. (1980). Mental illness and road traffic accidents. The Australian And New Zealand Journal Of Psychiatry, 14(1), 53-60. 
Bell, N.S., Amoroso, P.J., Yore, M.M., Smith, G.S., Jones, B.H. (2000). Self-reported risk-taking behaviors and hospitalization for motor vehicle injury among active duty army personnel. American Journal of Preventative Medicine, 18(3 Suppl), 85-95.

Blows, S., Ameratunga, S., Ivers, R.Q., Lo, S.K., Norton, R. (2005). Risky driving habits and motor vehicle driver injury. Accident Analysis and Prevention, 37(4), 619-624.

Buttiglieri, M. W., Woodson, M. I., Guenette, M., \& Thomson M. (1969). Driver accidents and the neuropsychiatric patient. Journal of Consulting and Clinical Psychology, 33(3), 381.

Crancer, A. Jr, \& Quiring, D. L. (1969). The mentally ill as motor vehicle operators.American Journal of Psychiatry, 126(6), 807-813.

Deery, H.A., Fildes, B.N. (1999). Young novice driver subtypes: relationship to high-risk behavior, traffic accident record, and simulator driving performance. The Journal of the Human Factors and Ergonomics Society, 41(4), 628-643.

Edlund, M. J., Conrad, C., \& Morris, P. (1989). Accidents among schizophrenic outpatients. Comprehensive Psychiatry, 30(6), 522-526.

Foley, D. J., Wallace, R. B., \& Eberhard, J. (1995). Risk factors for motor vehicle crashes among older drivers in a rural community. Journal of the American Geriatrics Society, 43(7), 776781.

Fong, G., Frost, D., Stansfeld, S. (2001). Road rage: a psychiatric phenomenon. Social Psychiatry and Psychiatric Epidemiology, 36(6), 277-286.

Gulliver, P., Begg, D. (2007). Personality factors as predictors of persistent risky driving behavior and crash involvement among young adults. Injury Prevention, 13(6), 376-381.

Karlsson, G., Halldin, J., Leifman, A., Bergman, H., Romelsjo, A. (2003). Hospitalization and mortality succeeding drunk driving and risky driving. Alcohol and Alcoholism, 38(3), 281286.

Koepsell, T. D., Wolf, M. E., McCloskey, L., Buchner, D.M., Louie, D., Wagner, E.H.,\& Thompson, R.S. (1994). Medical conditions and motor vehicle collision injuries in older adults. Journal of the American Geriatrics Society, 42(7), 695-700.

Kontogiannis, T. (2006). Patterns of driver stress and coping strategies in a Greek sample and their relationship to aberrant behaviors and traffic accidents. Accident Analysis and Prevention, 38(5), 913-924.

Lajunen, T., Sumer, N., Ozkan, T. (2001). Do symptoms of psychopathology predict a professional driver's involvement in traffic accidents? Journal of Traffic Medicine, 29(12):32-35.

Malta, L.S., Blanchard, E.B., Freidenberg, B.M. (2005). Psychiatric and behavioral problems in aggressive drivers. Behaviour Research and Therapy, 43(11), 1467-1484.

Mayer, R.E., Treat, J.R. (1977). Psychological, social and cognitive characteristics of high risk drivers: a pilot study. Accident Analysis and Prevention, (9), 1-8.

Nabi, H., Consoli, S.M., Chastang, J.F., Chiron, M., Lafont, S., Lagarde, E. (2005). Type A behavior pattern, risky driving behaviors, and serious road traffic accidents: a prospective study of the GAZEL cohort. American Journal of Epidemiology, 161(9), 864-870. 
Nabi, H., Rachid Salmi, L., Lafont, S., Chiron, M., Zins, M., Lagarde, E. (2007). Attitudes associated with behavioral predictors of serious road traffic crashes: results from the GAZEL cohort. Injury Prevention, 13(1), 26-31.

Parker, D., West, R., Stradling, S., Manstead, A.S. (1995). Behavioural characteristics and involvement in different types of traffic accident. Accident Analysis and Prevention, 27(4):571-581.

Rajalin, S. (1994). The connection between risky driving and involvement in fatal accidents. Accident and Analysis Prevention, 26(5), 555-562.

Schwebel, D.C., Severson, J., Ball, K.K., Rizzo, M. (2006). Individual difference factors in risky driving: the roles of anger/hostility, conscientiousness, and sensation-seeking. Accident and Analysis Prevention, 38(4):801-810.

Sullman, M.J.M., Meadows, M.L., Pajo, K.B. (2002). Aberrant driving behaviours amongst New Zealand truck drivers. Transportation Research Part F: Traffic Psychology and Behaviour, 5(3), 217-232.

Sumer, N. (2003). Personality and behavioral predictors of traffic accidents: testing a contextual mediated model. Accident Analysis and Prevention, 35(6), 949-964.

Turner, C., McClure, R. (2004). Quantifying the role of risk-taking behaviour in causation of serious road crash-related injury. Accident Analysis and Prevention, 36(3), 383-389.

Verschuur, W.L.G., Hurts, K. (2008). Modeling safe and unsafe driving behaviour. Accident Analysis and Prevention, 40(2), 644-656.

Waller, J.A. (1965). Chronic medical conditions and traffic safety: review of the California experience. New England Journal of Medicine, 273(26), 1413-20.

Wear, D. M. (1985). Mental disorders and motor traffic accidents in Wyoming. Dissertation Abstracts International, 46(6-B), 2082.

Wells, G. A., Shea, B., O'Connell, D., Peterson, J., Welch, V., Losos, M., \& Tugwell P. (2006). The Newcastle-Ottawa Scale (NOS) for assessing the quality of nonrandomized studies in meta-analyses. Retrieved http://www.ohri.ca/programs/clinical_epidemiology/oxford.htm

Wells-Parker, E., Ceminsky, J., Hallberg, V., Snow, R.W., Dunaway, G., Guiling, S., Williams, M., Anderson, B. (2002). An exploratory study of the relationship between road rage and crash experience in a representative sample of US drivers. Accident Analysis and Prevention, 34(3), 271-278. 